\title{
Comparison of the Effects of Epidural Clonidine and Fentanyl on Spinal Anaesthesia in Lower Abdominal and Lower Limb Surgeries - A Randomised Controlled Study from Delhi, India
}

\author{
Dhriti Chungkrang1, Mohandeep Kaur², Priyanka Singh ${ }^{3}$ \\ 1, 2, 3 Department of Anaesthesiology and Critical Care, ABVIMS, \\ Dr. RML Hospital, Baba Kharag Singh Marg, New Delhi, India.
}

\section{ABSTRACT}

\section{BACKGROUND}

Addition of epidural adjuvants like opioids or $\alpha 2$-adrenoreceptor agonists can enhance the effectiveness of local anaesthetics for surgical procedures on lower abdomen, pelvis, and lower limbs, by intensifying the block and prolonging the duration of analgesia. We wanted to compare the duration of spinal blockade (sensory and motor) and the degree of analgesia between epidural clonidine and fentanyl before giving spinal anaesthesia.

\section{METHODS}

A prospective double blind randomized comparative study was conducted among 100 patients (18 - 65 years) scheduled for elective lower abdomen and lower limb surgeries. Patients were divided into two groups. For C group - clonidine $0.75 \mathrm{ug} / \mathrm{kg}$ epidural given with spinal anaesthesia ( $5 \%$ bupivacaine), in Group F fentanyl was given $1.5 \mathrm{ug} / \mathrm{kg}$ epidural with $5 \%$ bupivacaine. The outcome measures were time of onset of sensory blockade, duration and level of sensory blockade, time to achieve highest blockade level, duration of motor blockade, vital parameters, and time of first rescue analgesia. All data was entered in MS excel and analysed. $\mathrm{P}$ value $<0.05$ was considered significant.

\section{RESULTS}

The demographic data (age, gender) were comparable in both the groups. The preoperative blood pressure, pulse rate, SpO2 were comparable. Clonidine group had significantly lesser mean time of onset of sensory block and motor block $(\mathrm{P}<0.001)$, higher duration of motor blockade $(\mathrm{P}<.0001)$ and higher time for first rescue analgesia $(\mathrm{P}<.0001)$ as compared to fentanyl group. The incidence of hypotension and bradycardia was more with clonidine group than with fentanyl group.

\section{CONCLUSIONS}

Clonidine $0.75 \mathrm{ug} / \mathrm{kg}$ is a better epidural adjuvant than fentanyl $1.5 \mathrm{ug} / \mathrm{kg}$ when given by intrathecal route with $5 \%$ bupivacaine in terms of mean time of onset and duration for both sensory and motor blockade. It also has better analgesic effect postoperatively. Whereas fentanyl is found to be safer in view of haemodynamic stability.

\section{KEY WORDS}

Clonidine, Fentanyl, Spinal Anaesthesia
Corresponding Author: Dr. Dhriti Chungkrang, Department of Anaesthesiology and Critical Care, ABVIMS, Dr. RML Hospital, Baba Kharag Singh Marg, New Delhi - 110001, India. E-mail: dhritichung4@gmail.com

DOI: $10.14260 /$ jemds/2021/351

How to Cite This Article:

Chungkrang $D$, Kaur $M$, Singh $P$. Comparison of the effects of epidural clonidine and fentanyl on spinal anaesthesia in lower abdominal and lower limb surgeries - a randomised controlled study from Delhi, India. $J$ Evolution Med Dent Sci 2021;10(22):1698-1702, DOI: $10.14260 /$ jemds $/ 2021 / 351$

Submission 18-01-2021,

Peer Review 26-03-2021,

Acceptance 31-03-2021,

Published 31-05-2021.

Copyright (C) 2021 JEMDS. This is an open access article distributed under Creative Commons Attribution License [Attribution 4.0 International (CC BY 4.0)] 


\section{BACKGROUND}

Neuraxial technique which includes spinal and epidural block, is a well-established regional anaesthetic technique commonly used for surgical procedures on lower abdomen, pelvis and lower limbs. It has the ability to maintain continuous anaesthesia after placement of an epidural catheter in the epidural space thus suitable for procedures of long duration. ${ }^{1}$ The addition of epidural adjuvants like opioids or $\alpha 2$ adrenoreceptor agonists can enhance the effectiveness of local anaesthetics by intensifying the block and prolonging the duration of analgesia. They also decrease the dose requirement of local anaesthetic, thus preventing side effects associated with large doses. ${ }^{1}$

Fentanyl is $\mu$ - opioid receptor agonist and its main site of action is substantia gelatinosa in the dorsal horn of spinal cord, where it blocks the neural fibres carrying pain impulses both at pre-synaptic and post synaptic levels and thereby enhances neuraxial anaesthesia. It has no effect on sympathetic and motor neurons and thus has an advantage over local anaesthetics.

Fields et al. ${ }^{2}$ showed that dorsal roots (primary afferent tissues) contain opioid binding sites and fentanyl may either act directly on the spinal nerve or by penetrating the dura mater to act at the spinal roots. When fentanyl is used alone, analgesia will not be enough and overdosing is needed, and it is found to be associated with pruritus, nausea, vomiting and respiratory depression. Addition of opioid to local anaesthetics gives the opportunity to use more diluted local anaesthetic solutions for better analgesia reducing its systemic toxicity risk and motor blockade effect of local anaesthetic drugs. ${ }^{3,4}$ Clonidine acts on pre and post synaptic sympathetic nerve terminal and central nervous system to decrease the sympathetic outflow and nor - epinephrine release to augment the effects of local anaesthetics in regional block. It produces analgesia through an opioid independent mechanism and may be an alternative to opioids. Clonidine also exerts vasoconstricting effect on smooth muscles, which results in a decreased absorption of the local anaesthetic agent and eventually prolongs the duration of analgesia.

Though clonidine provides intense and long-lasting analgesia, yet these effects are inadequate for surgical anaesthesia. Hence, clonidine has been used as an adjunct only to local anaesthetics. At high doses, it is associated with sedation, hypotension and bradycardia but no respiratory depression or other opioid - related side effects. ${ }^{1}$

Fentanyl and clonidine are used as adjuvant to both spinal and epidural local anaesthetic agents to improve the quality of analgesia after major abdominal surgeries and reduce the dose requirement of local anaesthetics. ${ }^{5}$

As per one study, use of clonidine epidurally before giving spinal blockade increases its duration to almost double. Use of fentanyl as an adjuvant epidurally or intrathecally is available but use of epidural fentanyl before spinal anaesthesia is limited to literature. Hence we need to compare the duration of spinal blockade (sensory and motor) and the degree of analgesia between Epidural clonidine and fentanyl before giving spinal anaesthesia.

\section{METHODS}

We conducted a prospective double blind randomized controlled study on 100 Patients (18 - 65 years) scheduled for elective lower abdomen and lower limb surgeries with ASA physical status I and II in the Department of Anaesthesiology from 1 / 11 / 2017 - 31 / 3 / 2019. $1^{\text {st }}$ November, 2017 - 31 $1^{\text {st }}$ March, 2019.

The study of Chhabra AR, et $\mathrm{al}^{6}$ observed mean value of total analgesia time in fentanyl group was $234.44 \pm 58.76 \mathrm{~min}$ and in clonidine group was $354 \pm 46.73 \mathrm{~min}$. Taking these values as reference, the minimum required sample size with $99 \%$ power of study and $1 \%$ level of significance is 10 patients in each study group. To reduce margin of error, total sample size taken is 100 ( 50 patients per group).

Patients were enrolled in the study after taking informed consent. Preoperative evaluation was done, and patients were randomly divided into two groups i.e. C group - given $0.75 \mathrm{ug} /$ $\mathrm{kg}$ clonidine in $5 \mathrm{ml}$ Normal saline intrathecal before giving spinal anaesthesia and F group - Given $1.5 \mathrm{ug} / \mathrm{kg}$ fentanyl in $5 \mathrm{ml}$ Normal saline intrathecal before giving spinal anaesthesia. The randomization was done by block randomization technique with sealed envelope system. Patients with coagulopathy, pre-existing neurological deficit, allergy to local anaesthetic solution, BMI $>30$, infection at puncture site and failed subarachnoid block were excluded from the study.

Time of onset of sensory blockade, duration and level of sensory blockade, time to achieve highest blockade level, duration of motor blockade, and vital parameters as systolic BP, Heart rate, Spo2 was noted intraoperatively. Time of requirement of first rescue analgesia was noted postoperatively. All the noted data was entered in MS excel spreadsheet. Data Analysis was done using statistical package for social sciences (SPSS) version 21.0. P value $<0.05$ was considered significant.

\section{Statistical Analysis}

Categorical variables were presented in number and percentage (\%) and continuous variables were presented as mean \pm SD and median. Normality of data was tested by Kolmogorov - Smirnov test. If the normality was rejected, then non parametric test was used.

Statistical tests were applied as follows -

1. Quantitative variables were compared using Independent t test / Mann - Whitney Test (when the data sets were not normally distributed) between the two groups.

2. Qualitative variables were compared using chi - Square test.

\section{RESULTS}

The mean age of Group C was $47.38 \pm 12.19$ years and Group F was $45.7 \pm 12.44$ years. $(\mathrm{P}=0.431)$ The gender distribution was comparable (male / female: $66 \%$ / $34 \%$ vs. $58 \%$ / $42 \%$, $\mathrm{P}=0.41)$. The baseline demographic and hemodynamic characteristics of the study population were comparable (Table 1). 


\begin{tabular}{|c|c|c|c|c|c|}
\hline & \multirow{2}{*}{ Demographic Characteristics } & \multicolumn{2}{|c|}{ Group } & \multirow{2}{*}{ Total $(\mathrm{N}=100)$} & \multirow{2}{*}{ P Value } \\
\hline & & $C(N=50)$ & $F(N=50)$ & & \\
\hline \multirow{7}{*}{ Age distribution (in years) } & $<=30$ & $9(18.00 \%)$ & $10(20.00 \%)$ & 19 (19.00 \%) & \multirow{5}{*}{0.925} \\
\hline & $31-40$ & $5(10.00 \%)$ & $7(14.00 \%)$ & $12(12.00 \%)$ & \\
\hline & $41-50$ & $14(28.00 \%)$ & $15(30.00 \%)$ & $29(29.00 \%)$ & \\
\hline & $51-60$ & $15(30.00 \%)$ & $13(26.00 \%)$ & $28(28.00 \%)$ & \\
\hline & $>60$ & $7(14.00 \%)$ & $5(10.00 \%)$ & $12(12.00 \%)$ & \\
\hline & Mean \pm Stdev & $47.38 \pm 12.19$ & $45.7 \pm 12.44$ & $44.36 \pm 12.56$ & 0421 \\
\hline & Median(IQR) & $48(40-56)$ & $45(39-57)$ & $45(35.500-56)$ & \multirow{3}{*}{0.41} \\
\hline \multirow{2}{*}{ Gender } & Female & $21(42.00 \%)$ & $17(34.00 \%)$ & $38(38.00 \%)$ & \\
\hline & Male & $29(58.00 \%)$ & $33(66.00 \%)$ & $62(62.00 \%)$ & \\
\hline \multirow{2}{*}{ Systolic blood pressure (mm Hg) } & Mean \pm Stdev & $135.92 \pm 11.34$ & $133.08 \pm 12.26$ & $135.2 \pm 15.18$ & \multirow{2}{*}{0.232} \\
\hline & Median(IQR) & $136(130-142)$ & $133.5(124-142)$ & $136(124-144)$ & \\
\hline \multirow{2}{*}{ Diastolic blood pressure (mm Hg) } & Mean \pm Stdev & $75.92 \pm 11.02$ & $74.38 \pm 9.7$ & $75.15 \pm 10.36$ & \multirow{2}{*}{0.652} \\
\hline & Median(IQR) & $78(67-80)$ & $78(67-80)$ & $78(67-80)$ & \\
\hline \multirow{2}{*}{ Heart rate (bpm) } & Mean \pm Stdev & $94.34 \pm 7.22$ & $91.08 \pm 11.35$ & $91.09 \pm 13.26$ & \multirow{2}{*}{0.101} \\
\hline & Median(IQR) & $96(90-98)$ & $90(82-99)$ & $92(80-100)$ & \\
\hline \multirow{2}{*}{$\mathrm{SpO}_{2}(\%)$} & Mean \pm Stdev & $100 \pm 0$ & $99.98 \pm 0.14$ & $99.99 \pm 0.1$ & \multirow{2}{*}{0.317} \\
\hline & Median(IQR) & $100(100-100)$ & $100(100-100)$ & $100(100-100)$ & \\
\hline
\end{tabular}

\begin{tabular}{|c|c|c|c|c|c|}
\hline & Variables & $C(N=50)$ & $F(N=50)$ & Total $(\mathrm{N}=100)$ & P Value \\
\hline \multirow{6}{*}{ Max level } & $\mathrm{T} 4$ & $2(4.00 \%)$ & $3(6.00 \%)$ & $5(5.00 \%)$ & \multirow{6}{*}{0.0003} \\
\hline & T5 & $10(20.00 \%)$ & $1(2.00 \%)$ & 11 (11.00 \%) & \\
\hline & T6 & $32(64.00 \%)$ & $26(52.00 \%)$ & $58(58.00 \%)$ & \\
\hline & $\mathrm{T} 7$ & $6(12.00 \%)$ & $5(10.00 \%)$ & 11 (11.00 \%) & \\
\hline & $\mathrm{T} 8$ & $0(0.00 \%)$ & 7 (14.00\%) & 7 (7.00 \%) & \\
\hline & T10 & $0(0.00 \%)$ & 8 (16.00\%) & $8(8.00 \%)$ & \\
\hline \multirow{4}{*}{$\begin{array}{l}\text { Time of sensory onset (in } \\
\text { minutes) }\end{array}$} & $<=4$ & $43(86.00 \%)$ & $10(20.00 \%)$ & $53(53.00 \%)$ & \multirow{2}{*}{$<.0001$} \\
\hline & $4.1-8$ & $6(12.00 \%)$ & $26(52.00 \%)$ & $32(32.00 \%)$ & \\
\hline & Mean \pm Stdev & $3.41 \pm 1.56$ & $6.96 \pm 2.68$ & $5.18 \pm 2.82$ & \multirow{5}{*}{$<.0001$} \\
\hline & Median(IQR) & $3(2.533-4)$ & $7(5-9)$ & $4(3-7)$ & \\
\hline \multirow{5}{*}{$\begin{array}{l}\text { Time of two segment } \\
\text { regression }\end{array}$} & $45-100$ & $7(14.00 \%)$ & $44(88.00 \%)$ & $51(51.00 \%)$ & \\
\hline & $101-150$ & $32(64.00 \%)$ & $5(10.00 \%)$ & $37(37.00 \%)$ & \\
\hline & $>150$ & 11 (22.00\%) & $1(2.00 \%)$ & 12 (12.00 \%) & \\
\hline & Mean \pm Stdev & $132.4 \pm 28.31$ & $80.14 \pm 25.53$ & $106.27 \pm 37.54$ & \multirow{2}{*}{$<.0001$} \\
\hline & Median(IQR) & $133(120-150)$ & $74(60-96)$ & $100(70-136)$ & \\
\hline \multicolumn{6}{|c|}{ Table 2. Comparison of Variables between Group C and F } \\
\hline
\end{tabular}

\begin{tabular}{|c|c|c|c|c|c|}
\hline & Variables & $C(N=50)$ & $F(N=50)$ & Total $(\mathrm{N}=100)$ & P Value \\
\hline \multirow{7}{*}{$\begin{array}{l}\text { Onset of motor (in } \\
\text { minutes) }\end{array}$} & $<=4$ & $10(20.00 \%)$ & $0(0.00 \%)$ & $10(10.00 \%)$ & \multirow{4}{*}{0.000004} \\
\hline & $4.1-8$ & 36 (72.00\%) & $9(18.00 \%)$ & $45(45.00 \%)$ & \\
\hline & $8.1-12$ & $3(6.00 \%)$ & $20(40.00 \%)$ & $23(23.00 \%)$ & \\
\hline & $>12$ & $1(2.00 \%)$ & $21(42.00 \%)$ & $22(22.00 \%)$ & \\
\hline & Mean \pm Stdev & $5.92 \pm 2.19$ & $11.82 \pm 3.58$ & $8.87 \pm 4.18$ & \multirow{3}{*}{$<.0001$} \\
\hline & Median(IQR) & $6(5-7)$ & $12(10-15)$ & $8(5-12)$ & \\
\hline & $<=100$ & $0(0.00 \%)$ & $5(10.00 \%)$ & $5(5.00 \%)$ & \\
\hline \multirow{5}{*}{$\begin{array}{l}\text { Duration of motor } \\
\text { blockade (in } \\
\text { minutes) }\end{array}$} & $101-200$ & $6(12.00 \%)$ & $31(62.00 \%)$ & $37(37.00 \%)$ & \multirow{3}{*}{$<.0001$} \\
\hline & $201-300$ & $25(50.00 \%)$ & $14(28.00 \%)$ & $39(39.00 \%)$ & \\
\hline & $301-400$ & $19(38.00 \%)$ & $0(0.00 \%)$ & $19(19.00 \%)$ & \\
\hline & Mean \pm Stdev & $290.24 \pm 56.14$ & $172.44 \pm 46.33$ & $231.34 \pm 78.27$ & \multirow{3}{*}{$<.0001$} \\
\hline & Median(IQR) & $300(240-320)$ & $175(135-210)$ & $221(175-300)$ & \\
\hline \multirow{5}{*}{$\begin{array}{c}\text { Time of first rescue } \\
\text { analgesia (in hours) }\end{array}$} & $<=3$ & $0(0.00 \%)$ & $18(36.00 \%)$ & $18(18.00 \%)$ & \\
\hline & $3.1-6$ & 27 (54.00 \%) & $32(64.00 \%)$ & $59(59.00 \%)$ & \multirow[t]{2}{*}{$<.0001$} \\
\hline & $>6$ & $23(46.00 \%)$ & $0(0.00 \%)$ & $23(23.00 \%)$ & \\
\hline & Mean \pm Stdev & $6.11 \pm 1.04$ & $3.59 \pm 1.02$ & $4.85 \pm 1.63$ & \multirow[b]{2}{*}{$<.0001$} \\
\hline & Median(IQR) & $6(5-6.833)$ & $3.5(3-4.167)$ & $5(3.500-6)$ & \\
\hline
\end{tabular}
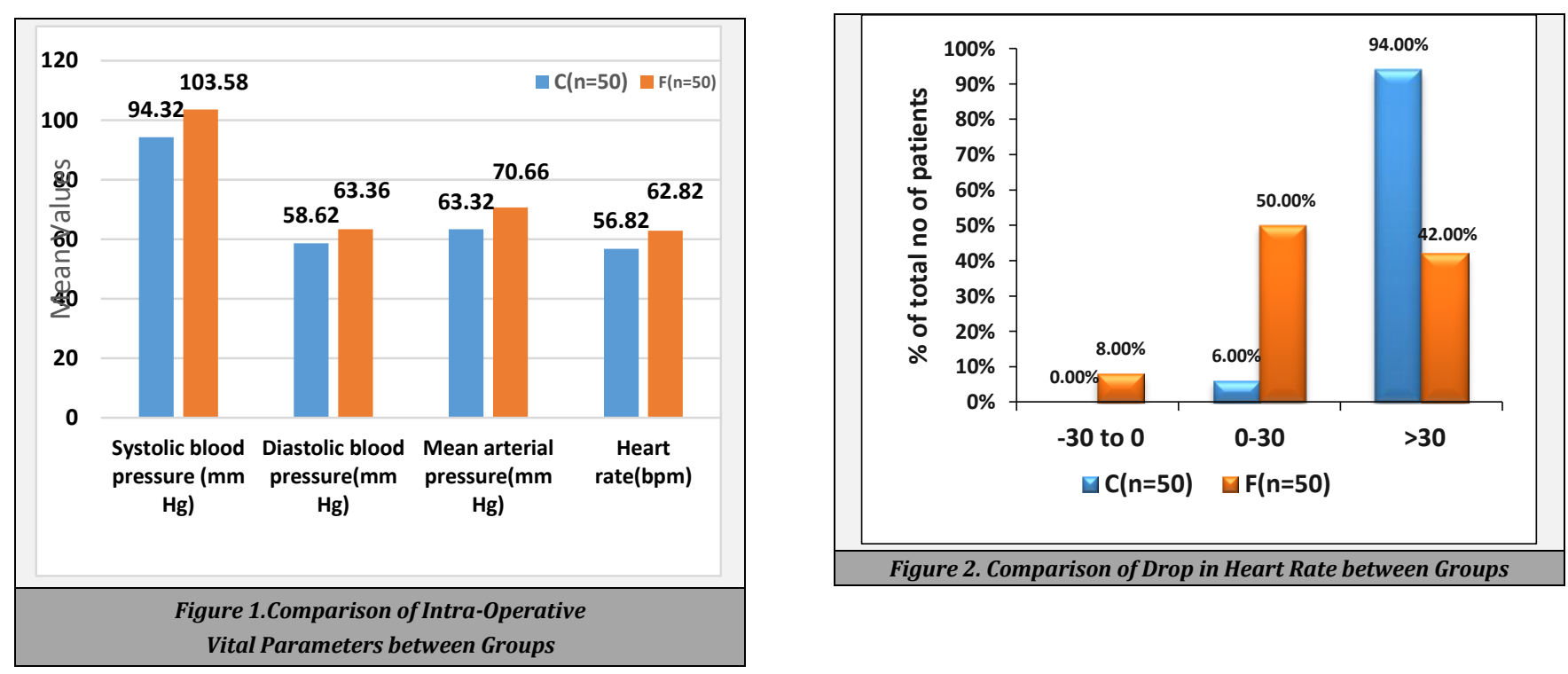

Figure 2. Comparison of Drop in Heart Rate between Groups 
The intra-op vital characteristics among the two groups have been shown in Figure 1. There were no significant fluctuations and thus they were comparable among the two groups. Compared to Group C, Group F had significantly more patients with max levels at T6, T7, T8, and T10 (92\% vs. $76 \%$, $\mathrm{P}=0.0003$ ), significantly higher mean time of sensory onset (minutes) $(6.96 \pm 2.68$ vs. $3.41 \pm 1.56, \mathrm{P}<.0001)$, and significantly lesser time of two segment regression (80.14 \pm 25.53 vs. $132.4 \pm 28.31, \mathrm{P}<.0001$ ) (Table 2). Compared to Group C, Group F had significantly higher onset of motor (minutes) (11.82 \pm 3.58 vs. $5.92 \pm 2.19, \mathrm{P}<.0001)$, significantly lesser duration of motor blockade (minutes) $(172.44 \pm 46.33$ vs. $290.24 \pm 56.14, \mathrm{P}<.0001$ ), and significantly lesser time of first rescue analgesia (hours) (3.59 \pm 1.02 vs. $6.11 \pm 1.04, \mathrm{P}<$ .0001) (Table 3).

As compared to clonidine group, fentanyl group had significantly lower drop-in heart rate $(23.22 \pm 16.64$ vs. 41.66 $\pm 6.8, \mathrm{P}<.0001$ ). In clonidine group, the drop - in heart rate was $>30$ in $94.00 \%$ cases and $0-30$ in $6.00 \%$ of the cases. In fentanyl group, the drop-in heart rate was $0-30$ in $50 \%$ of the cases, $>30$ in $42.00 \%$ of the cases, and 30 to 0 in $8.00 \%$ cases. There was a significant difference between two groups in terms of drop-in heart rate $(\mathrm{P}<.0001)$. (Figure 2$)$

\section{DISCUSSION}

In our study, the mean age distribution and gender $(\mathrm{P}=0.410)$, among the two groups was comparable ( $47.38 \pm 12.19$ vs 45.7 $\pm 12.44, \mathrm{P}=0.431$ ). Preoperatively, in the clonidine group, the mean SBP, DBP, HR, and Sp02 was $135.92 \pm 11.34 \mathrm{~mm} \mathrm{Hg}$, $75.92 \pm 11.02 \mathrm{~mm} \mathrm{Hg}, 94.34 \pm 7.22 \mathrm{bpm}$, and $100 \pm 0$, respectively, whereas in the fentanyl group the mean SBP, DBP, HR and SpO2 was $133.08 \pm 12.26 \mathrm{~mm} \mathrm{Hg}, 74.38 \pm 9.7 \mathrm{~mm}$ $\mathrm{Hg}, 91.08 \pm 11.35 \mathrm{bpm}$ and $99.98 \pm 0.14$, respectively. The preoperative vital parameters among the two groups - group $\mathrm{C}$ and group F were comparable ( $\mathrm{P}>0.05)$. The comparability in the baseline characteristics ensured that the outcomes were purely due to interventions and were not by chance.

As per a study by Khadse PB et al. $^{2}$ comparing clonidine and fentanyl as an adjuvant to bupivacaine in unilateral spinal, mean maximum cephalad spread of block till T12 was achieved in $63 \%$ patients in fentanyl group and $53 \%$ patients in clonidine group due to lesser doses of the adjuvant drugs used. So, the maximum level of sensory block obtained was comparable and statistically insignificant. Whereas, in the present study in clonidine group, maximum sensory level was achieved up to T6 in $64 \%$ patients, followed by T5 (in $20 \%$ ), T7 (in $12 \%$ ) and T4 (in $4 \%$ ). Among fentanyl group, maximum sensory level was achieved up to $\mathrm{T} 6$ in $52 \%$ patients, followed by T10 (in $16.00 \%$ ), T8 (in $14 \%$ ), T7 (in $10 \%$ ), T4 (in $6 \%$ ) and T5 (in $2 \%$ ). There was a significant difference between two groups in terms of maximum level of sensory blockade (P $=0.0003$ ). So, present study stood contrast to above study.

In a study by Prasad R et al. ${ }^{7}$ comparing the effects of epidural clonidine in spinal anaesthesia, the highest sensory dermatome level achieved was $\mathrm{T} 5$ in clonidine group seen in $53.3 \%$ and T6 in fentanyl group seen in $46 \%$, which was clinically significant. So, this study correlates with present study. Nigam S et al. ${ }^{8}$ studying analgesic efficacy of epidural clonidine with fentanyl as an adjuvant reported that the mean onset time of adequate sensory analgesia at T10 dermatome was higher $(6.87 \pm 0.35 \mathrm{~min})$ in fentanyl group than clonidine group ( $6.58 \pm 0.66 \mathrm{~min}$ ). In our study, as compared to clonidine group, fentanyl group had significantly higher mean time of onset of sensory block $(6.96 \pm 2.68$ vs $3.41 \pm 1.56, \mathrm{P}<.0001)$.

Agarwal $\mathrm{S}$ et al. ${ }^{1}$ also reported lower two segment regression of sensory block in fentanyl group as compared to clonidine group $(\mathrm{P}=0.001)$. Nigam $\mathrm{S}$ et al. ${ }^{8}$ reported that fentanyl group had significantly lower time of two segment regression $(80.14 \pm 25.53$ vs $132 \pm 28.41)$ as compared to clonidine group $(\mathrm{P}=0.001)$. In our study, as compared to clonidine group, fentanyl group had significantly lower time of two segment regression of sensory block (80.14 \pm 25.53 vs $132.4 \pm 28.31, \mathrm{P}<.0001)$. Findings of these studies were in accordance with the present study. As per study by Kohli V et al. ${ }^{9}$ where time taken to two segment regression of sensory block was higher in fentanyl group as compared to clonidine group (157 \pm 9.24 vs $153.00 \pm 10.22, \mathrm{P}<0.001)$ which was in contrast to the present study.

\section{Motor Blockade Characteristics}

Agarwal S et al. ${ }^{1}$ reported that onset of motor blockade and the duration of motor blockade was accelerated with epidural fentanyl when compared to epidural clonidine with statistically significant difference $(P=0.031)$ and $(P=.001)$, which was in contrast to the present study.

Whereas in the present study, as compared to clonidine group, fentanyl group had significantly higher mean time of onset of motor block $(11.82 \pm 3.58$ vs $5.92 \pm 2.19$, $\mathrm{P}<.0001)$, but lower mean duration of motor blockade $(172.44 \pm 46.33$ vs $290.24 \pm 56.14, \mathrm{P}<.0001)$, proving clonidine as a better adjuvant drug than fentanyl.

\section{Hemodynamic Effects}

In a study by Agarwal S et al. ${ }^{1}$ intraoperative fall in heart rate was statistically significant in clonidine group compared to fentanyl group. Bradycardia ( $<55$ beats / min) was observed in 6 patients of clonidine group while no bradycardia was seen in fentanyl group. In the present study also, similar statistically significant changes in heart rate were observed, i.e. more drop in heart rate with clonidine and less in fentanyl group (23.22 \pm 16.64 vs $41.66 \pm 6.8, \mathrm{P}<.0001)$.

However, study by Kohli $\mathrm{V}$ et al. ${ }^{9}$ ( where lesser doses of clonidine 0.75 ug and fentanyl 37.5 ug were used as adjuvants with $0.75 \%$ ropivacaine in epidural space) - reported that side effects like hypotension and bradycardia were seen only in 10 $\%$ of patients in clonidine group and $6.67 \%$ in fentanyl group, which was not significant and was in contrast to our study. This could be due to probably higher doses of clonidine and fentanyl used in our study.

In our study, intra-operatively fentanyl group patients had significantly higher SBP $(103.58 \pm 10.2$ vs $94.32 \pm 8.98, \mathrm{P}<$ $0.0001)$; DBP ( $63.36 \pm 7.47$ vs. $58.62 \pm 7.28, \mathrm{P}=0.002$ ); $\mathrm{MAP}$ (70.66 \pm 7.67 vs. $63.32 \pm 7.88, \mathrm{P}<.0001)$ and lesser drop in heart rate $(62.82 \pm 6.65$ vs. $56.82 \pm 5.81, \mathrm{P}<.0001)$ compared to clonidine group.

So, the results of the present study correlate with that of study by Agarwal S et al. ${ }^{1}$ which reported that intraoperative 
fall in heart rate was statistically significant in patients of clonidine group when compared to fentanyl group. Bradycardia ( $<55$ beats / $\mathrm{min}$ ) was observed in 6 patients of clonidine group which responded to injection atropine $6 \mathrm{mg}$ i.v

\section{Rescue Analgesia}

In a study by Saini $S$ et al. ${ }^{10}$ where comparison between epidural clonidine with fentanyl as an adjunct to $0.25 \%$ ropivacaine for post-operative analgesia showed the time for first rescue analgesia as more with clonidine (670 - 780 minutes) than with fentanyl (650 - 700 minutes) which was not statistically significant. $(\mathrm{P}>.05)$.

Also in a study by Agarwal $\mathrm{S}$ et al. ${ }^{1}$ where comparison of clonidine and fentanyl as an adjunct to $0.75 \%$ ropivacaine for limb surgeries, the mean duration of analgesia was significantly extended in patients who were given clonidine i.e. (360 - 380 minutes) as when compared to fentanyl (340 - 360 minutes). $(\mathrm{P}<.001)$

The difference in duration was observed due to higher doses used by Saini S et al. ${ }^{10}$ i.e. clonidine $2 \mathrm{ug} / \mathrm{kg}$ and fentanyl 1ug / kg compared to study by Agarwal S et al. ${ }^{1}$ where $50 \mathrm{ug}$ fentanyl and 50 ug clonidine as adjuvant with $0.75 \%$ ropivacaine.

Study by Prasad R et al. ${ }^{7}$ on studying the efficacy of epidural clonidine with normal saline in epidural space showed the time of first rescue analgesia as $(299 \pm 43.38)$ minutes in clonidine group and $(152.50 \pm 21.04)$ minutes in fentanyl which was statistically significant. $(\mathrm{P}<.0001)$.

In the present study, mean time for first request of rescue analgesia was $6.11 \pm 1.04$ hours in clonidine group, and $3.59 \pm$ 1.02 hours in fentanyl group, which was statistically significant $(\mathrm{P}<.001)$. So, as per this parameter our study was comparable to the above studies.

Thus, the present study showed that clonidine group had significantly lesser mean time of onset of sensory block and motor block $(\mathrm{P}<0.001)$, higher duration of motor blockade and also time period for first rescue analgesia was significantly more in clonidine group $(\mathrm{P}<.0001)$ as compared to fentanyl group.

Results showed clonidine to be superior to fentanyl as adjuvant drug as it produced rapid onset of action and better block characteristics. However, clonidine caused significantly higher bradycardia and hypotension as compared to fentanyl group. So, instability in hemodynamic parameters was reported more with clonidine as compared to fentanyl.

\section{CONCLUSIONS}

Epidural adjuvant $0.75 \mu \mathrm{g} / \mathrm{kg}$ clonidine is better when compared to fentanyl $1.5 \mu \mathrm{g} / \mathrm{kg}$ given before intrathecal bupivacaine for spinal anaesthesia with regard to mean time of onset of sensory and motor block, time for two segment regression, duration of motor blockade and time of first rescue analgesia. So, clonidine can be preferred over fentanyl. However, greater hemodynamic instability observed in clonidine group points out to further research on the topic to be carried out with lesser dose of clonidine $(<0.75 \mu \mathrm{g} / \mathrm{kg})$ to have enhanced effects without haemodynamic instability.

\section{Limitations}

Firstly, it was conducted on patients of lower abdominal and lower limb surgeries to avoid differences in the perception of pain. So, results of clonidine and fentanyl could not be assessed in other surgeries, because the perception of postoperative pain would certainly differ depending on the level of surgery. Secondly, results of occurrence of other side effects such as headache, nausea, vomiting, urinary retention, sedation, convulsions and pruritus were not compared between the two groups.

Data sharing statement provided by the authors is available with the full text of this article at jemds.com.

Financial or other competing interests: None.

Disclosure forms provided by the authors are available with the full text of this article at jemds.com.

\section{REFERENCES}

[1] Agarwal S, Gupta K, Gupta PK, et al. Clonidine versus fentanyl as adjuvant to $0.75 \%$ ropivacaine for epidural anaesthesia for lower limb surgeries: a comparative evaluation. Int J Res Med Sci 2016;4(8):3606-10.

[2] Khadse PB, Chhatrapati S, Kamble T. Comparison of clonidine and fentanyl as an adjuvant to bupivacaine in unilateral spinal anaesthesia. Int J Res Med Sci 2018;6(2):5217.

[3] Bajwa SJS, Bajwa SK, Kaur J, et al. Admixture of clonidine and fentanyl to ropivacaine in epidural anaesthesia for lower abdominal surgery. Anesth Essays Res 2010;4(1):9-14.

[4] Cousins MJ, Mather LE. Intrathecal and epidural administration of opioids. Anesthesiology 1984;61(3):276-310.

[5] Torpy JM, Lynm C, Golub RM. JAMA patient page. Regional anaesthesia. JAMA 2011;306(7):781.

[6] Chhabra AR, Jagtap SR, Dawoodi SF. Comparison of clonidine versus fentanyl as an adjuvant to intrathecal ropivacaine for major lower limb surgeries: a randomized double-blind prospective study. Indian J Pain 2013;27(3):170-4.

[7] Prasad R, Rao RR, Turai A, et al. Effect of epidural clonidine on characteristics of spinal anaesthesia in patients undergoing gynaecological surgeries: a clinical study. Indian J Anaesth 2016;60(6):398-402.

[8] Nigam S, Rastogi S, Tyagi A, et al. A comparative study for the analgesic efficacy and safety profile of fentanyl versus clonidine as an adjuvant to epidural ropivacaine $0.75 \%$ in lower abdominal surgeries. Anesth Essays Res 2017;11(3):692-6.

[9] Kohli AV, Bhan S, Gulati S, et al. A comparative evaluation of clonidine, fentanyl and combination of both as adjucants to ropivacaine in epidural block for perineral and lower limb surgeries. JK Science 2016;18(3):127-31.

[10] Saini S, Patodi V, Sethi SK, et al. Comparison of caudal epidural clonidine with fentanyl as an adjuvant to ropivacaine $0.25 \%$ for postoperative analgesia in children undergoing various infraumbilical surgeries: a prospective randomized study. Ains Shams J Anesthesiol 2016;9(4):493-500. 